\title{
MOBILIÁRIO URBANO COM MADEIRA DE REFLORESTAMENTO: DESENVOLVIMENTO DE PROJETO E PRODUÇÃO DE MODELO EM ESCALA REDUZIDA
}

\author{
Ana Laura Alves, (UNESP); Victor Augusto Vieira, (UNESP); \\ Letícia Yuri Nakata, (UNESP); Hudson Guerrero Michelan, (USC); \\ Tomás Queiroz Ferreira Barata, (UNESP).
}

\author{
PALAVRAS CHAVE \\ Mobiliário urbano; Sustentabilidade; Eucalipto; Design.
}

KEY WORDS

Urban furniture; Sustainability; Eucalyptus; Design.

\section{RESUMO}

A produção e o consumo responsável de produtos inovadores, que incorporem o conceito de sustentabilidade, é uma demanda crescente. O conhecimento técnico-científico do designer na produção de mobiliário urbano para espaços públicoso coloca como importante instrumento de aproximação na interface objeto e o homem. O objetivo deste estudo foi o de desenvolver um projeto de mobiliário urbano para tornar o espaço público, área da Central de Laboratórios, em um local receptivo, favorecendo a permanência e possibilitando a integração entre a instalação pré-existente e os indivíduos que circulam por aquele espaço. Para tanto, foram projetados mesa e banco, e, produzido o modelo da mesa em escala reduzida (1:5). Além de considerar os aspectos relativos ao local de instalação do mobiliário e às necessidades existentes, o projeto teve como desafio o aproveitamento da matéria-prima disponível, ripas de eucalipto residuais de outro projeto. O mobiliário urbano, associado a aspectos relacionados à sua função (usabilidade, conforto), pode estimular e facilitar a convivência entre os frequentadores

\section{ABSTRACT}

de espaços públicos.

Production and responsible consumption of innovative products that incorporate the concept of sustainability is a growing demand. The technical and scientific knowledge of the designer in the production of urban furniture for public spaces puts as an important tool in approaching object interface and man. The objective of this study was to develop a urban furniture project to make the public space, Laboratories Center area, in a receptive place, favoring the permanence and promoting integration between pre-existing installation and individuals who circulate that space. For this purpose, table and bench were developed and produced the table of small-scale model (1:5). In addition to considering the aspects related to the site of the furniture installation and existing needs, the project had as challenge the use of available raw material, waste eucalyptus strips from another project. The urban furniture, associated with aspects related to its function (usability, comfort), can stimulate and facilitate coexistence among people frequenting public places. 


\section{INTRODUÇÃO}

A madeira serrada, oriunda de florestas plantadas, pode ser considerada uma alternativa para a demanda de matéria-prima de fonte renovável na fabricação de mobiliário urbano (PONCE, 1995). Considerando a utilização de matéria-prima de fontes renováveis, o potencial do Eucalipto é grande, embora seja um recurso pouco e inadequadamente explorado. Com o emprego de tecnologias adequadas em toda a cadeia produtiva do Eucalipto, desde o cultivo até o produto final, este poderia participar efetivamente da redução das perdas e da pressão sobre florestas nativas. Outro aspecto relevante é o fato de o mercado receber uma madeira de qualidade, com características homogêneas e com ciclo de corte de período mais curto que outras madeiras (MENDES; ALBUQUERQUE, 2000; FAGUNDES, 2003).

De acordo com o Programa Nacional de Florestas (PNF) e a Sociedade Brasileira de Silvicultura (SBS), especificamente a produção de móveis de madeira, o consumo é de aproximadamente $59 \%$ da madeira maciça serrada e $41 \%$ da industrializada, portanto, existe um desiquilíbrio entre a oferta de madeira plantada e a demanda por parte da indústria de base florestal (BNDS, 2007).

No Brasil, a indústria de mobiliários produzidos a partir de matéria-prima florestal apresenta significativos avanços tecnológicos, associados a um importante aumento na demanda por produtos ambientalmente corretos e com certificação florestal (ALVES et. al, 2009). Sendo assim, os diversos segmentos da tecnologia de produção de madeira de floretas plantadas, desde a pesquisa que avalia a escolha das espécies mais indicadas, melhoramento genético dessas espécies até a exploração e tecnologia de processamento, merecem atenção (MENDES; ALBUQUERQUE, 2000; FAGUNDES, 2003).

A produção e o consumo responsável de produtos inovadores que incorporem o conceito de sustentabilidade, no seu ciclo de vida, é uma demanda social, econômica e ambiental crescente. Neste contexto, o designer é considerado como um agente no processo de transformações culturais e econômicas, e dessa forma, com um conceito mais amplo de atuação envolvendo em seus projetos além de outros preceitos, a responsabilidade com a sustentabilidade (preservação dos recursos naturais, qualidade de vida do homem e viabilidade econômica) (PAPANEK, 1995; MANZINI; VEZZOLI, 2002; BARATA, 2011; FERROLLI, 2012; ICSID, 2013; ALVES et al; 2015).

A participação do designer na produção de mobiliário para áreas públicas o coloca como importante ferra- menta de aproximação na interface objeto e o homem. A relação estabelecida entre a população, o espaço público e o seu mobiliário urbano é peculiar, de forma que o espaço não se restringe a ser o lugar comum às pessoas, mas sobretudo, desempenha uma função subjetiva, a de despertar práticas sociais em um local de encontros, fazendo com que o coletivo aproveite de forma prazerosa (MONTENEGRO, 2005; JOHN; REIS, 2010; OLIVEIRA, 2011).

Segundo alguns pesquisadores, as características das edificações, assim como, a funcionalidade dos espaços devem ser previamente analisadas para que haja respectivamente compatibilidade entre as formas e uso adequado do espaço público. Portanto, para o êxito da instalação de mobiliário em áreas públicas, a relação entre o mobiliário urbano e as edificações do entorno, deve ser criteriosamente avaliada (LONDON, 2000; JOHN; REIS, 2010). Para Montenegro (2005), ao se relacionar com o entorno e ser projetado para desempenhar funções, o mobiliário urbano influencia na percepção dos usuários sobre o espaço (MONTENEGRO, 2005).

A área da Central de Laboratórios (CL) da Faculdade de Arquitetura, Artes e Comunicação (FAAC), da Universidade "Júlio" de Mesquita Filho, Campus Bauru, tem um fluxo diário e intenso de alunos. No entanto, embora exista espaço disponível entre as edificações, não há no local um mobiliário que dê suporte à integração entre a estrutura arquitetônica, a área disponível e a permanência confortável dos alunos na área. Constatada a demanda, surgiu na Disciplina de Oficina de Madeira, do Curso de Design, o propósito de desenvolver um projeto para tornar o espaço público receptivo, favorecer a permanência e possibilitar a integração entre a instalação pré-existente e o público que circula por aquele espaço. Para tanto, foram projetados mesa e banco e produzido o modelo da mesa, em escala reduzida (1:5).

\section{METODOLOGIA}

A concepção do projeto se baseou no conceito de modularidade e melhor aproveitamento do espaço disponível. Uma vez estabelecido que o mobiliário a ser desenvolvido para a área externa, da Central de Laboratórios, seria uma mesa e que essa deveria ser triangular, o projeto recebeu o nome de Mesapi. A denominação foi inspirada na palavra "Mosapyr", que significa três na língua dos índios Tupi Guarani, presentes na região de Bauru. A forma 
da mesa foi assim definida buscando um melhor arranjo de uma ou mais mesas, juntas ou não, entre os bancos de concreto existentes no espaço e os de madeira que fazem parte do projeto. A mesa foi idealizada para acomodar seis pessoas e os bancos, duas.

A matéria-prima disponibilizada pela Disciplina de Oficina de Madeira, Laboratório Didático de Materiais e Protótipos (LDMP), ripas de eucalipto, é uma madeira de fonte renovável produzida na região onde será executado o protótipo e posteriormente o mobiliário. $\mathrm{O}$ uso da madeira de eucalipto é uma proposta resultante da parceria entre a Faculdade de Arquitetura, Artes e Comunicação - FAAC/ UNESP, campus Bauru e a Estação Experimental de Bauru (EEB), pertencente ao Instituto Florestal de São Paulo (IF). Importante ressaltar que as ripas são sobras de outro projeto desenvolvido no laboratório, portanto, o modelo será produzido com sobra de madeira (ripas).

A partir da definição do produto e da matéria-prima, realizou-se uma revisão bibliográfica a respeito de mobiliário urbano, eucalipto e ciclo de vida dos produtos produzidos com esta madeira. Além disso, produtos similares foram analisados, assim como, a matéria-prima utilizada, o processo de produção, o impacto ambiental e o design.

\subsection{Material.}

2. 1. 1. Matéria-prima: Ripas de eucalipto;

2. 1. 2. Materiais: Lápis de carpinteiro; Papel sulfite; Filme plástico; Cola para madeira; Lixa para madeira; Verniz;

2. 1. 3. Equipamentos: Lixadeira circular (lixa 60); Lixadeira roto orbital pneumática (lixa 80); Serra de arco.

\subsection{Métodos.}

O processo de desenvolvimento do projeto e de produção do modelo reduzido pode ser didaticamente dividido em etapas: Análise de similares; Observação das características das edificações e do espaço; Registro das dimensões do local; Geração de alternativas através de sketches; Modelagem virtual e imagens "renderizadas" no software paramétrico Solid Works; Desenhos executivos dos planos e do produto montado; Impressão do gabarito na escala 1:5; Transformação da madeira; Execução do projeto - modelo em escala reduzida (montagem; acabamento); Fotografia do modelo.

\section{RESULTADOS E DISCUSSÕES}

A Lei 10.098/2000 define o termo mobiliário urbano como "conjunto de objetos nas vias e espaços públicos, superpostos ou adicionados aos elementos da urbanização ou da edificação (BRASIL, 2000). Contudo, o caráter utilitário faz parte do conceito de mobiliário urbano, definido por Montenegro (2005), como objetos com a finalidade de proporcionar comodidade e conforto aos usuários. De acordo com Alfonzo (2005), o conforto está relacionado à facilidade, conveniência e satisfação do usuário em utilizar determinado espaço. A presença de um mobiliário pode influenciar na escolha de um determinado espaço público, considerado mais confortável e agradável (ALFONZO, 2005; MONTENEGRO, 2005).

A funcionalidade do mobiliário está diretamente relacionada à definição do mesmo, portanto, a sua existência condicionada ao desempenho das funções para as quais foi projetado (GUEDES, 2005; BRANCAGLION, 2006). Aspectos utilitários e de adequação do projeto ao usuário são fundamentais para que o mobiliário cumpra sua função e possa ser adequada e amplamente utilizado, satisfazendo as necessidades do público alvo (GUEDES, 2005; MONTENEGRO, 2005; BRANCAGLION, 2006; JOHN; REIS, 2010; PIZZATO, 2013).

\subsection{Levantamento de Projetos Similares.}

Realizou-se uma análise crítica de produtos similares a respeito do material empregado, modo de produção, impacto ambiental, design e inovação. O mobiliário pode ser de tela aramada, concreto, metal, tecido, dentre outros materiais, como por exemplo, ripas de madeira, matéria -prima empregada neste estudo. $O$ intuito da análise de similares (Figura 1) foi o de verificar, entre outros aspectos, como o mobiliário urbano pode ser disposto e organizado em um espaço, a aplicação de diferentes matérias-primas.

Figura 1: Análise de produtos similares.

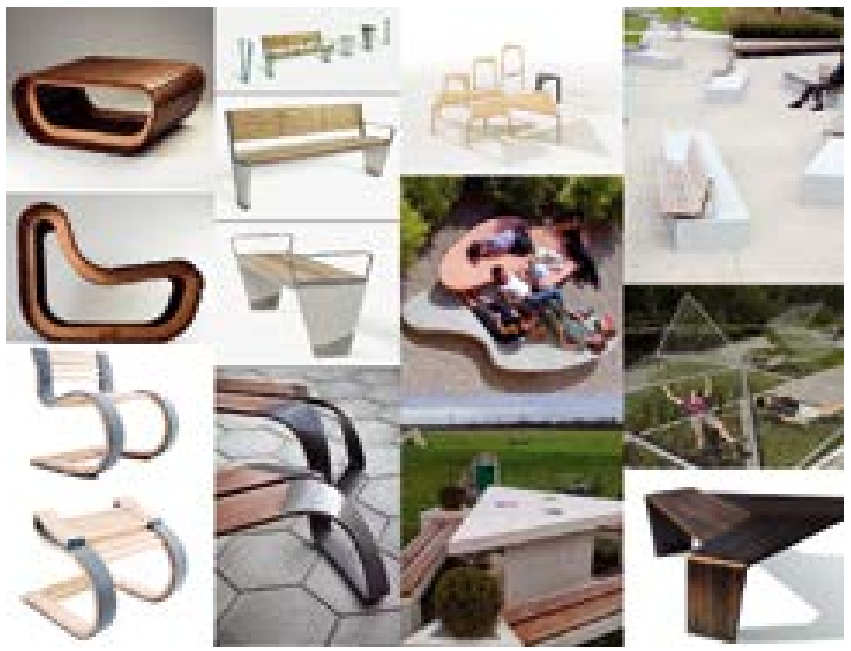

Fonte: http://www.pinterest.com 


\subsection{Processo de Desenvolvimento de Projeto .}

A concepção formal e o conceito estético do projeto resultou de estudos de modularidade e aproveitamento de espaço. Após a definição do local, Central de Laboratórios, e das necessidades de seus usuários, optou-se por desenvolver uma mesa com forma triangular por permitir alguns arranjos (Figura 2). Ao projeto atribuiu-se o nome Mesapi, tendo como inspiração a palavra "Mosapyr", que significa três na língua dos índios Tupi Guarani, presentes na região de Bauru.

Figura 2: Central de Laboratórios.

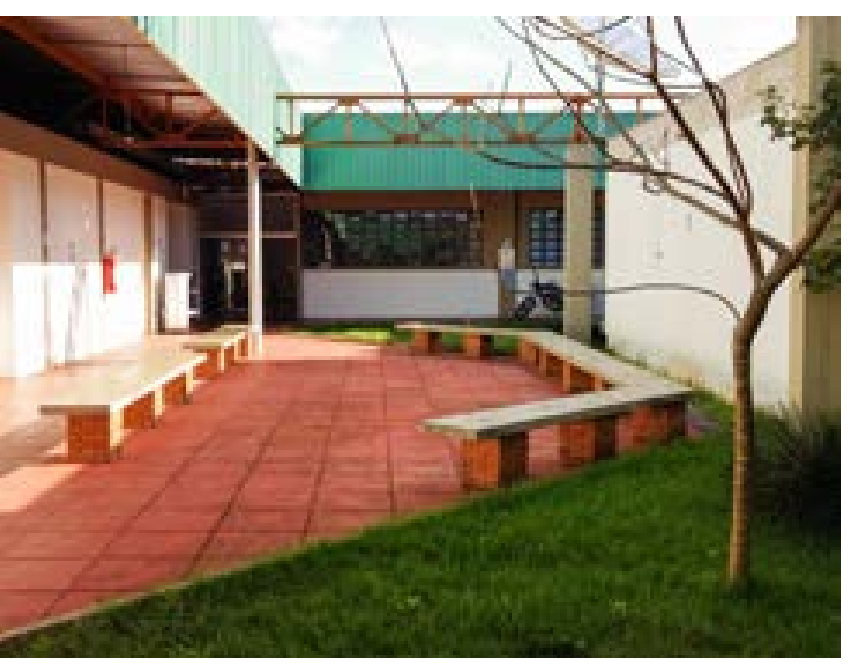

Fonte: Autores.

A etapa de criação de possíveis alternativas para o projeto Mesapi se deu por meio de sketches manuais, os quais foram base para a modelagem virtual 3D dos produtos no software paramétrico Solid Works, como também de rendering e desenho técnico (Figuras 3, 4 e 5).

Na área da Central de Laboratórios, existe entre as edificações um espaço que permite a instalação de três mesas separadas, que poderão também, compor uma única mesa usando as três em conjunto. O ambiente poderá ser configurado de diversas maneiras, de acordo com a necessidade e o número de usuários (alunos) do momento. Através do software paramétrico Solid Works, foram feitas simulações virtuais do mobiliário (Figura 6). Além de considerar os aspectos relativos ao local de instalação das mesas e dos bancos e às necessidades existentes, o projeto teve como desafio, o aproveitamento da matéria-prima disponível no LDMP, ripas de eucalipto residuais de outro projeto.
Figura 3: Rendering da mesa no software paramétrico Solid Works. Rendering do banco com textura de madeira.

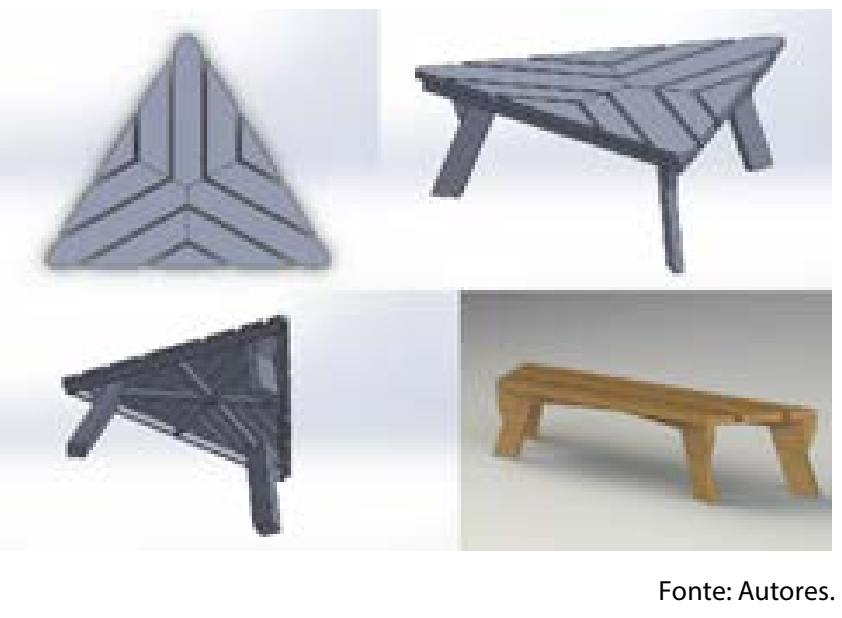

Figuras 4 e 5: Desenhos técnicos com as dimensões gerais da mesa e do banco.
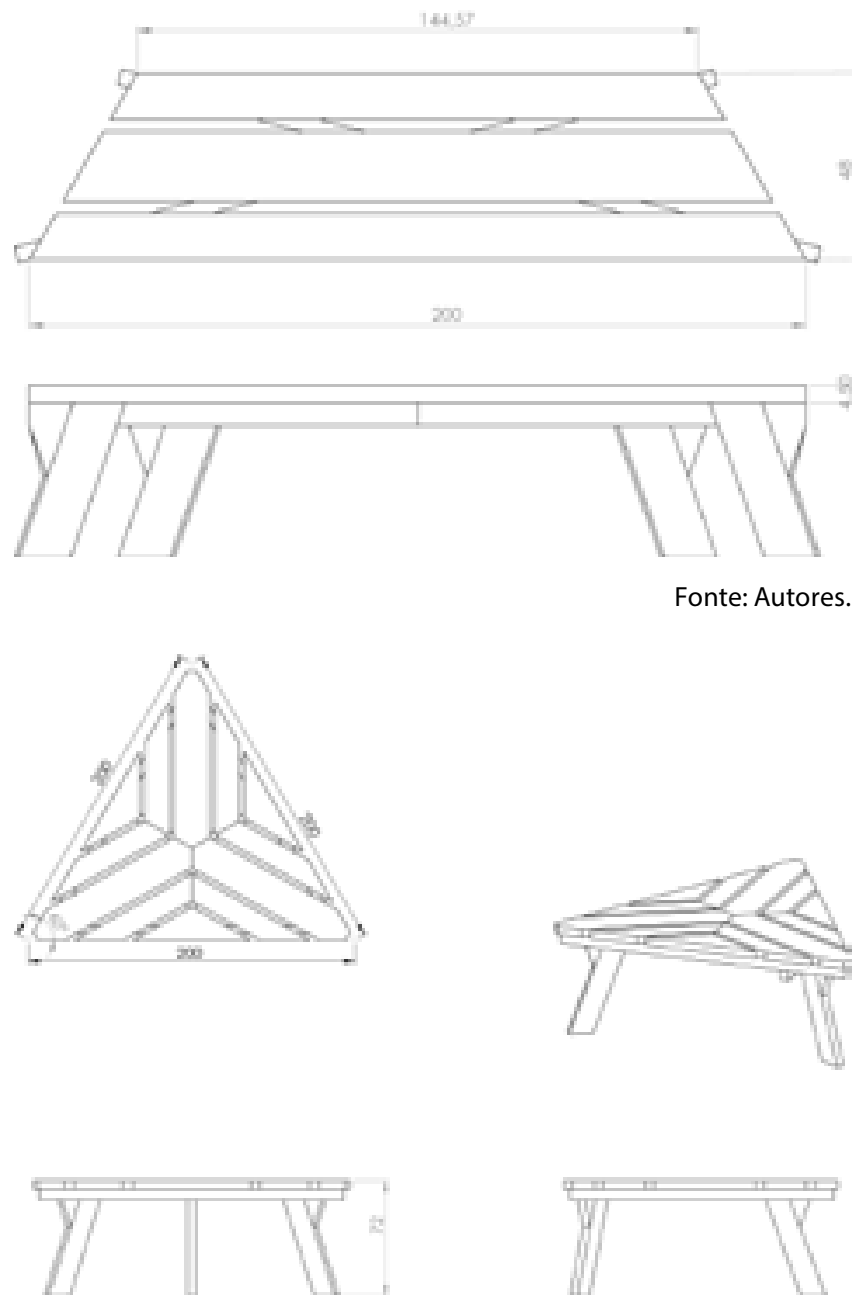

Fonte: Autores. 
Figura 6: Simulação virtual do mobiliário urbano no espaço escolhido.

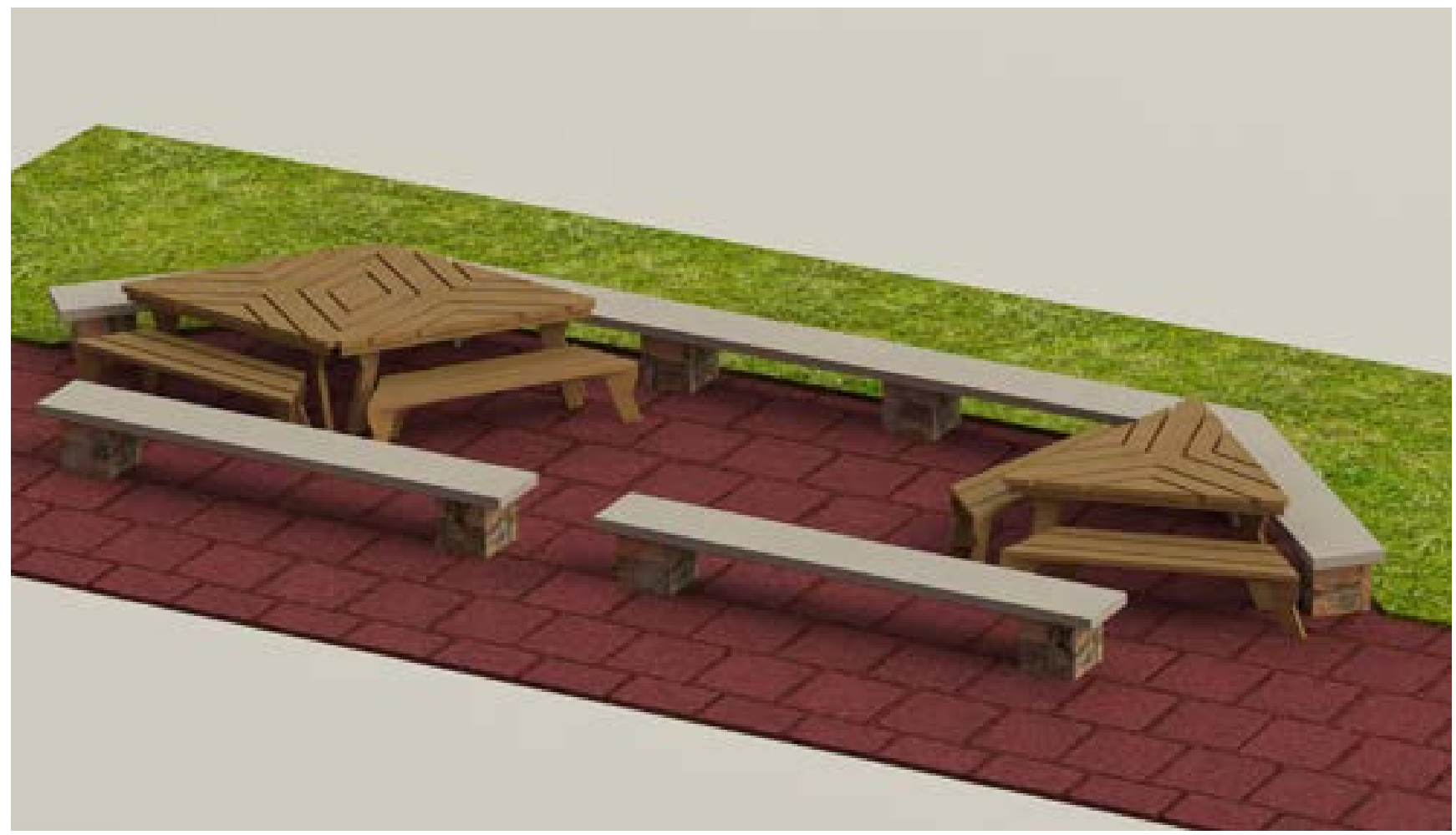

Fonte: Autores.

O fato de ser um mobiliário para área externa, dois aspectos importantes foram considerados: o escoamento da água proveniente das chuvas e a redução do acúmulo de resíduo. A configuração estabelecida entre as ripas (arranjo e o espaçamento entre as ripas) foi o recurso empregado.

\subsection{Elaboração de modelo em escala reduzida.}

Para iniciar o processo de transformação da madeira fez-se a seleção das ripas compatíveis com o projeto e em seguida, a transposição do desenho técnico das peças sobre as ripas (Figura 7).

O corte das peças foi executado com serra de fita e o refinamento com lixadeira circular (lixa 60) em algumas partes e nas demais com lixa manual (lixas 220, 400). Para o nivelamento de algumas ripas foi usada a lixadeira roto orbital pneumática (lixa 80). A serra de arco, fixada na bancada, foi empregada para o corte dos encaixes angulados (ripas do suporte do tampo) (Figura 8).

Na montagem do modelo, a princípio fez-se a limpeza das peças com ar comprimido para retirar todo o resíduo proveniente do corte e refinamento das ripas de madeira. Houve uma pré-montagem do modelo com a finalidade de verificar os encaixes.
Figura 7: Seleção das ripas; transposição do desenho técnico nas ripas; corte em serra de fita.

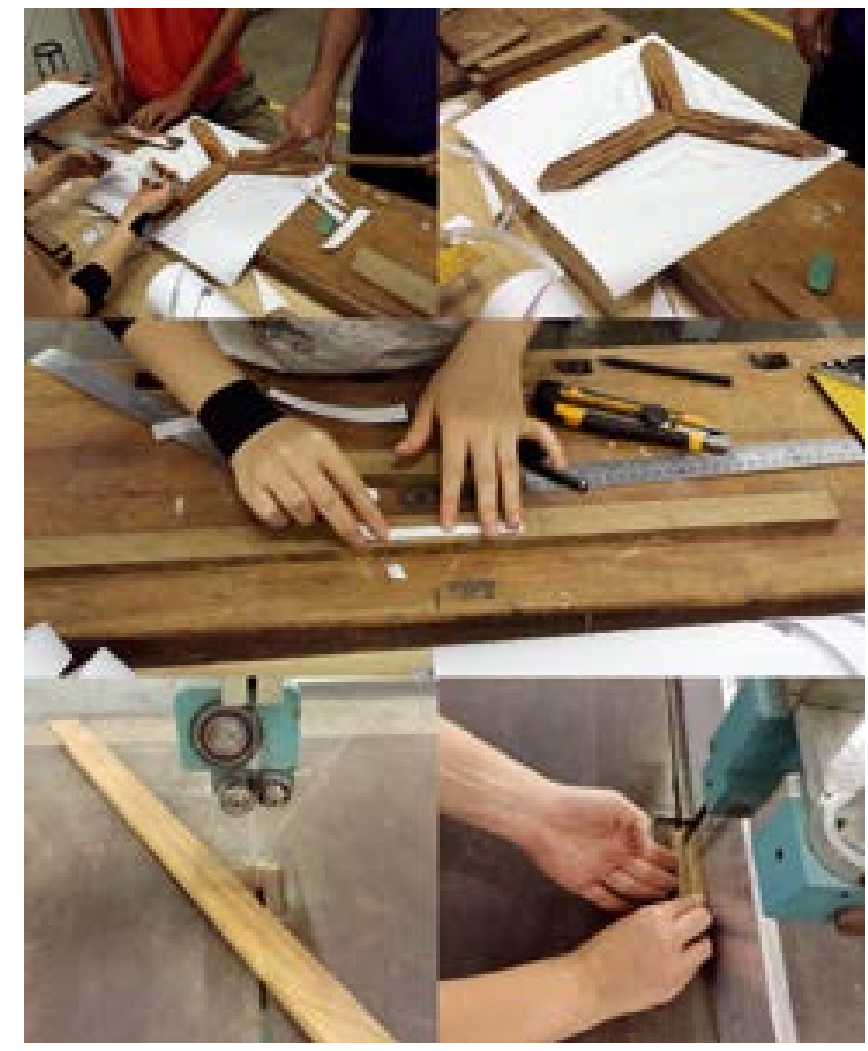

Fonte: Autores. 
Figura 8: Refinamento com lixadeira circular e manual; nivelamento com lixadeira roto orbital pneumática; corte angulado dos encaixes com a serra de arco.

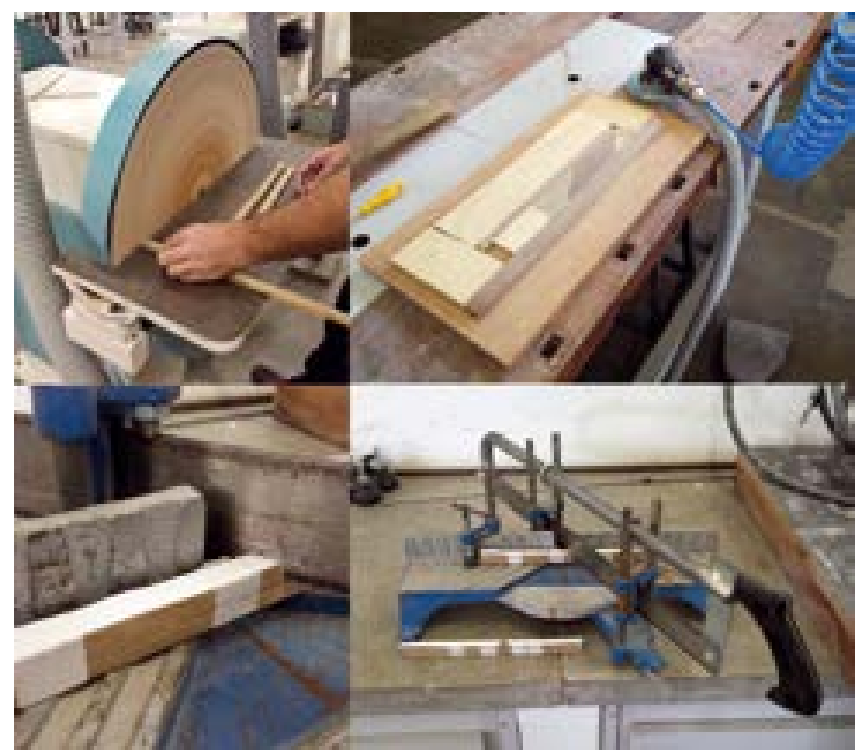

Fonte: Autores.

Entre o gabarito e as peças do modelo foi colocado um filme plástico de espessura desprezível, a fim de facilitar a remoção do modelo. Posteriormente, iniciou-se a colagem das peças da estrutura da mesa. Para tanto, empregou-se um gabarito de madeira formado por quatro peças, criado para estabilizar, gerar tensão entre as peças durante a colagem (Figura 9). O gabarito consiste de uma base e três peças para pressionar as laterais, sendo que a última somente foi pregada sobre a base após a finalização da colagem dos componentes da estrutura da mesa.

Figura 9: Pré-montagem do modelo; construção do gabarito de madeira para estabilizar as peças durante a colagem.

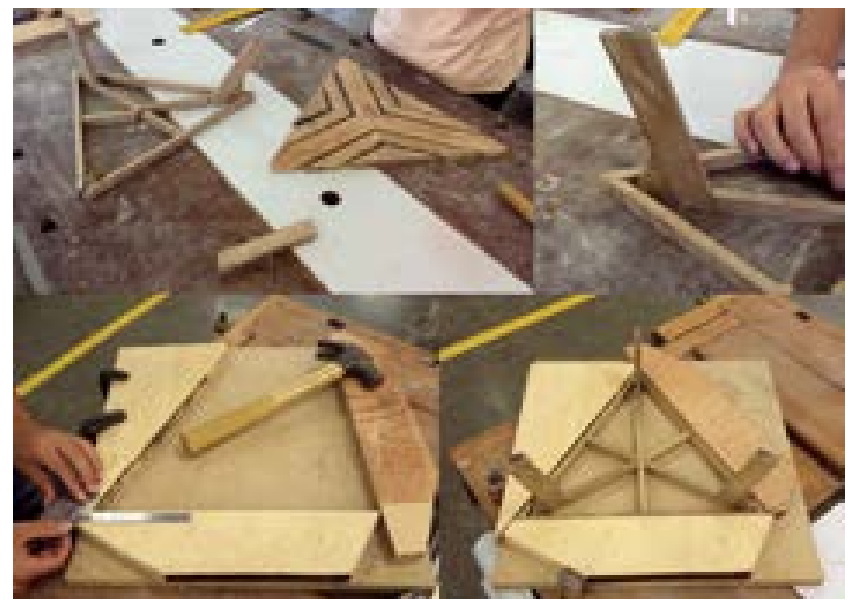

Fonte: Autores.
Além disso, para garantir a fixação ideal entre as peças, foram usados pesos e sargentos. Após 48 horas, foram coladas as peças do tampo da mesa sobre a estrutura, partindo do centro para as arestas. O processo de acabamento foi iniciado 24 horas depois de finalizada a montagem/ colagem do tampo da mesa (Figura 10).

Figura 10: Colagem da estrutura da mesa.

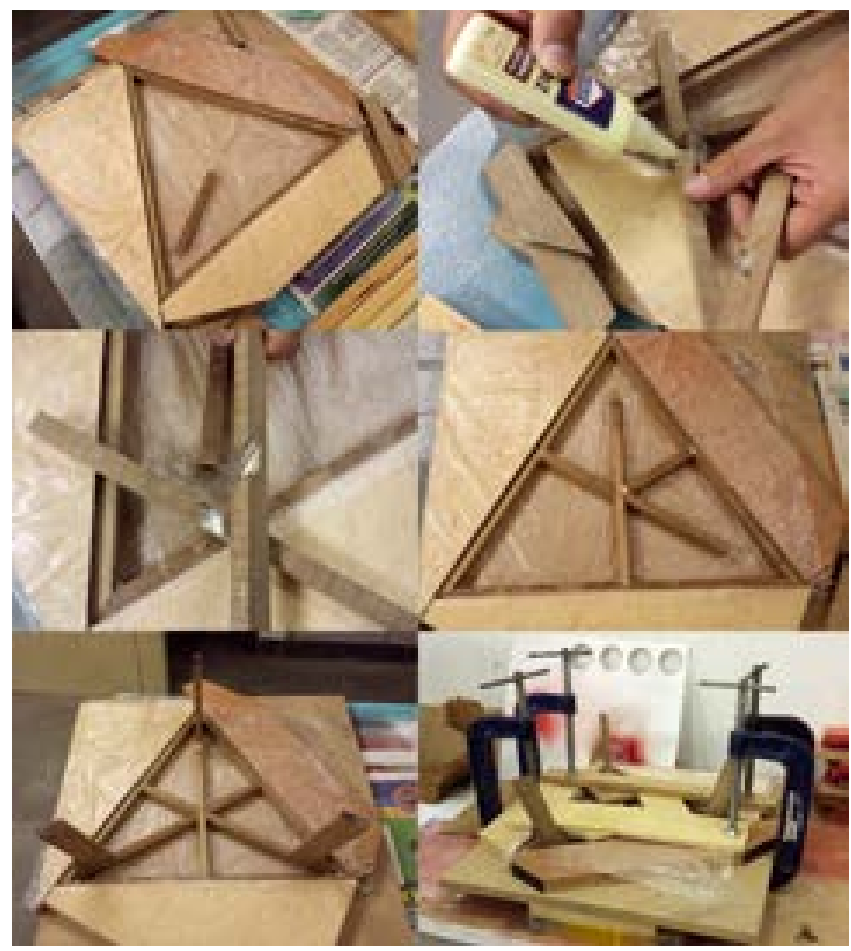

Fonte: Autores.

Figura 11: Finalização do processo de colagem da mesa (tampo); para o acabamento, houve a aplicação de verniz marítimo acetinado a base d'água.

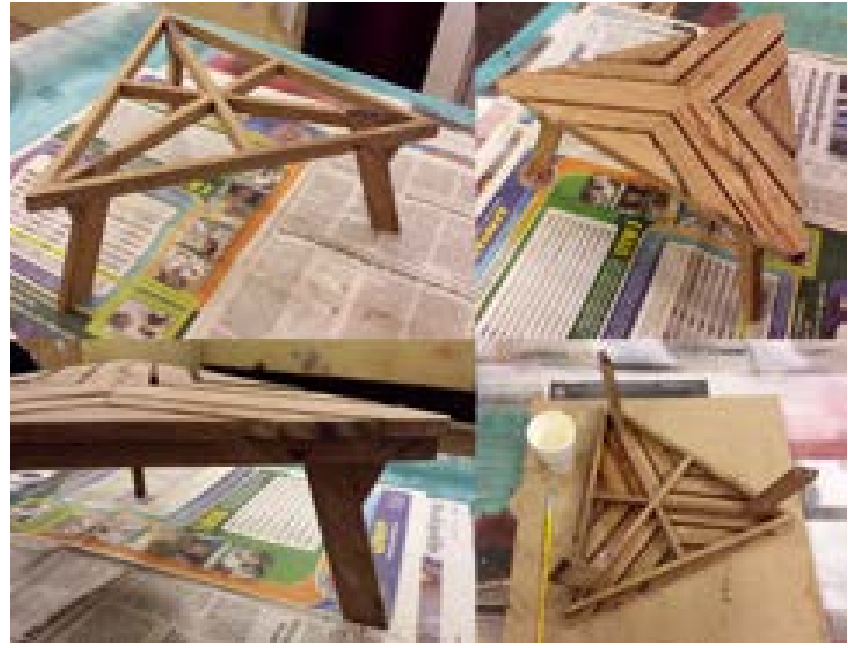

Fonte: Autores. 
O acabamento do modelo da mesa foi feito por meio de lixamento manual (lixa 400) até obter uma superfície lisa e uniforme o que reduz o acúmulo de resíduo, facilita a limpeza, proporciona uma maior durabilidade do mobiliário e conforto na utilização do mesmo. O modelo foi limpo com ar comprimido e, em seguida, realizada a aplicação de duas camadas de verniz marítimo acetinado a base d'água, Sayerlack Aquaris, com pincéis. Entre uma aplicação e outra de verniz houve um intervalo de 8 horas (Figura 11).

\section{Conclusão}

O mobiliário urbano, associado a aspectos relacionados à sua função (usabilidade/conforto), pode favorecer a convivência entre os usuários e a permanência desses em espaços públicos. Neste contexto, o projeto Mesapi teve como propósito desenvolver um mobiliário para tornar o espaço público em um local receptivo. $O$ projeto atingiu uma conquista adicional com a aplicação do conceito de modularidade e a escolha da madeira de reflorestamento, o Eucalipto, como matéria-prima. Vale ressaltar que durante o processo de desenvolvimento de um projeto, a produção de modelos em escala reduzida é fundamental para verificar fatores como os sistemas de encaixes, a usabilidade, a dimensão volumétrica e a estética de um produto. Além disso, essa etapa projetual proporciona o aprimoramento do conhecimento técnico no uso de equipamentos e no processamento de matéria-prima.

\section{REFERÊNCIAS}

1. ALFONSO, A. A.To Walk or Not Walk? The Hierarchy of Walking Needs. Environment and Behavior.n.37, p.808-836, 2005.

2. ALVES, A. L.; FERRERO, G.C.; SANTOS,G.F.; VALARELLI, I.D.; BARATA, T. Q. F. Uso sustentável de bambu em design: Estudo de caso de protótipos de sousplat com uso de resíduo de bambu. Fourth International Conference on Integration of Design, Engineering and Management for innovation (IDEMI), Florianópolis, 2015.

3. ALVES, R.; JACOVINE,L.; CYRILLO, F.; PIRES, V.; ALBINO, A. Percepção sobre o uso de madeira reflorestada nos móveis pelos consumidores do polo de ubá (MG). FLORESTA, 2009. Disponível em: http://ojs.c3sl.ufpr.br/ojs2/index.php/floresta/article/view/15364/10322. Acesso em: 20 de setembro de 2015
4. BARATA, T. Q. F. “Ensino e Sustentabilidade: Uma experiência didática no desenvolvimento do design de produtos "mais sustentáveis". VI Congresso Internacional de Pesquisa em Design, Lisboa, 2011.

5. BRANCAGLION, R. L. Equipamentos urbanos, design e identidade sócio-cultural: análise e proposta para a cidade do núcleo Bandeirante no D.F. Dissertação de Mestrado em Arquitetura e Urbanismo, Universidade de Brasília, D.F., 2006.

6. BRASIL. LEI N 10.098, de 19 de novembro de 2000. Estabelece normas gerais e critérios básicos para a promoção da acessibilidade das pessoas portadoras de deficiência ou com mobilidade reduzida, e dá providências. Diário Oficial da República Federativa do Brasil, Brasília, D.F., 20 de dez. 2000.

7. FAGUNDES, H. A. V. Diagnóstico da produção de madeira serrada e geração de resíduos do processamento de madeira de florestas plantadas no Rio Grande do Sul. Porto Alegre: PPGEC/UFRGS, 2003.

8. FERROLLI, P. C. M. Uso de modelos e protótipos para auxílio na análise da sustentabilidade no Design de Produtos. GEPROS. Gestão de Produção, Operações e Sistemas, n.3, p.107-125, 2012.

9. GUEDES, J B. Design no Urbano: Metodologia de Análise Visual de Equipamentos no Meio Urbano. Tese de Doutorado em Desenvolvimento Urbano, Universidade Federal de Pernambuco, 2005.

10. INTERNACIONAL COUNCIL OF SOCITIES OF INDUSTRIAL DESIGN. Definition Of Design. Disponível em: http:// www.icsid.org/about/articles.htm. Acesso em: 23 de outubro de 2015.

11. JOHN, N.; REIS, A. T. Percepção, Estética e Uso do Mobiliário Urbano. Gestão e Tecnologia de Projetos, vol. 5, n.2, 2010.

12. LONDON, N.Govemment Office for. Streets for All: a Guide to the Management of London's Streets. London: English Heritage, 2000.

13. MANZINI, E.;VEZZOLI,C.O desenvolvimento de Produtos Sustentáveis: os requisitos ambientais dos 
produtos industriais. São Paulo: EDUSP, pp. 368, 2002.

14. MENDES, L. M.; ALBUQUERQUE, C. E. C. Aspectos técnicos e econômicos da indústria brasileira de chapas de fibra e de partículas. Revista da Madeira, Curitiba, n. 53, p.14-22, 2000.

15. MONTENEGRO, G. A produção do mobiliário urbano em espaços públicos: desenho do mobiliário nos projetos de reordenamento das obras do RN. Dissertação de Mestrado em Arquitetura e Urbanismo, Universidade Federal do Rio Grande do Norte, Natal, 2005.

16. OLIVEIRA, S. V. A Disciplina de Mobiliário Urbano e Valores de Vida nas Cidades. In: Desenhando o futuro, Congresso Nacional de Design, Bento Gonçalves, RS, p. 1-9, 2011.

17. PAPANEK, V. Arquitetura e design: ecologia e ética. Edições 70, Lisboa, pp. 256, 1995.

18. PIZATO, G. Z. A. Design e emoção na utilização do mobiliário urbano em espaços públicos. Tese de Doutorado em Engenharia de Produção, Universidade Federal do Rio Grande do Sul, Porto Alegre, 2013.

19. PONCE, R. H. Madeira Serrada de Eucalipto: desafios e perspectivas. In: Seminário Internacional de Utilização de Madeira de Eucalipto para Serraria, São Paulo, p. 50-8, 1995.

20. ROSA, S. E. S; CORREA, A. R.; LEMOS, M; L. F.; BARROSO, D. V. BNDS Setorial, Rio de Janeiro, n. 25, p.65-106, 2007. 